\title{
The effect of nutrient profiles of the Dietary Approaches to Stop Hypertension (DASH) diets on blood pressure and bone metabolism and composition in normotensive and hypertensive rats
}

\author{
Lorna Doyle ${ }^{1}$ and Kevin D. Cashman ${ }^{1,2 *}$ \\ ${ }^{1}$ Department of Food and Nutritional Sciences and ${ }^{2}$ Department of Medicine, University College, Cork, Ireland
}

(Received 9 May 2002 - Revised 22 November 2002 - Accepted 2 January 2003)

\begin{abstract}
Hypertension has been associated with abnormalities of $\mathrm{Ca}$ and bone metabolism. Consequently, dietary strategies aimed at reducing blood pressure may also benefit bone health; however, this issue has received little attention. Therefore, the objective of the present study was to investigate the effect of two antihypertensive-type diets on blood pressure and bone metabolism and composition in normotensive (Wistar-Kyoto NHsd, WKY) and hypertensive (spontaneously hypertensive NHsd, SHR) rats. Thirty WKY and thirty SHR male rats, 14 weeks old, were separately randomized by weight into three groups of ten rats each. One group from each strain was given a control diet while the other two groups were fed two anti-hypertensive (high fruit and vegetable $(\mathrm{F} / \mathrm{V})$ and high fruit and vegetable and low-fat dairy produce (combination)) diets for 8 weeks. SHR rats were significantly $(P<0.01)$ heavier than WKY rats. Blood pressure and femoral length, width, dry weight, ash, $\mathrm{Ca}, \mathrm{Mg}, \mathrm{P}$ and bone mineral mass were significantly $(P<0.0001)$ greater in SHR than WKY rats, but were unaffected by diet, irrespective of strain. While markers of bone formation (serum osteocalcin) and bone resorption (urinary pyridinoline and deoxypyridinoline) were similar in both strains, these markers were significantly $(P<0.05)$ lower (28-31, 16-23, 31-33\% respectively) in the SHR rats fed the combination diet relative to those fed the control and F/V diets. Bone turnover in WKY rats was unaffected by diet. In conclusion, these findings suggest that the combination diet may benefit bone metabolism in hypertensive animals. However, as blood pressure was unaffected by this diet, the mechanism by which it reduced bone turnover requires further investigation.
\end{abstract}

Bone: Hypertension: Dietary intervention

Hypertension has been associated with abnormalities of $\mathrm{Ca}$ and bone metabolism in human subjects (McCarron et al. 1980; Cappuccio et al. 1999) and rats (McCarron et al. 1981, 1985; Pörsti, 1992). For example, lower circulating levels of 1,25-dihydroxycholecalciferol and reduced duodenal $\mathrm{Ca}$ absorption, bone density and bone $\mathrm{Ca}$ content have been reported in hypertensive rats as compared with normotensive rats (McCarron et al. 1985; Lucas et al. 1986; Blakeborough et al. 1990). In human subjects, reduced serum ionized $\mathrm{Ca}$ levels and increased levels of $\mathrm{Ca}$ and cyclic AMP in urine and increased 1,25-dihydroxycholecalciferol and parathyroid hormone in serum have been associated with hypertension (McCarron et al. 1980; Brickman et al. 1990; Jorde et al. 2000). MacGregor \& Cappuccio (1993) have hypothesized that the increased urinary $\mathrm{Ca}$ excretion in hypertensive patients is compensated not by increased intestinal absorption of $\mathrm{Ca}$, but by that liberated by resorption of bone, and that hypertensive patients are thus more prone to bone demineralization, bone fracture and osteoporosis.

Recent evidence suggests that dietary modification can positively influence blood pressure regulation (Svetkey et al. 1999; Dakshinamurti \& Dakshinamurti, 2001; Fleet, 2001). For example, the findings of the original Dietary Approaches to Stop Hypertension (DASH) study and the subsequent DASH-Sodium study suggest that increasing the fruit and vegetable intake, either alone (in the case of the DASH trial) or in combination with increased consumption of low-fat dairy produce (referred to as the 'combination diet' (Comb), used in both DASH and

\footnotetext{
Abbreviations: DASH, Dietary Approaches to Stop Hypertension; Comb, high fruit and vegetable and low-fat dairy produce diet; Dpyr, deoxypyridinoline; F/V, high fruit and vegetable diet; pyr, pyridinoline; SHR, spontaneously hypertensive; WKY, Wistar-Kyoto.

* Corresponding author: Professor K. D. Cashman, fax + 35321 4270244, email k.cashman@ucc.ie
} 
DASH-Sodium trials), can lower both systolic and diastolic blood pressure in individuals with high-normal and mildly elevated blood pressure (Appel et al. 1997, 2001; Moore et al. 1999; Conlin et al. 2000; Vollmer et al. 2001). Furthermore, a recent report arising from the original DASH study has suggested that the DASH Comb diet can also reduce serum homocysteine levels (Appel et al. 2000) and plasma total-, LDL- and HDL-cholesterol levels (Obarzanek et al. 2001) in these normotensive and mildly hypertensive subjects. The mechanism by which this type of diet lowers these independent risk factors for cardiovascular disease is still unclear (Appel et al. 2000). Consumption of the DASH Comb diet in place of the more typical Western-type diet will lead to substantially increased intake of several nutrients, including $\mathrm{Ca}, \mathrm{Mg}, \mathrm{K}$ and various vitamins, all of which have been investigated individually for their anti-hypertensive effects (Allender et al. 1996; Touyz \& Milne, 1999; Dakshinamurti \& Dakshinamurti, 2001), as well as increased intake of several non-nutrients, including various phytochemicals. It is likely that the anti-hypertensive effects of the DASH Comb diet are due to the increased intake of one or more of these nutrients and/or food components, by their interaction, or indeed by their displacement of other food components typical of a Western-type diet.

It is possible that in addition to having a beneficial effect on the regulation of blood pressure and circulating homocysteine and cholesterol levels, the DASH Comb diet may also have a beneficial effect on $\mathrm{Ca}$ and bone metabolism, and thus bone health, particularly in hypertensive subjects, who may be at increased risk of osteoporosis (Cappuccio et al. 2000). This is based on the fact that many of the nutrients that are rich in the DASH Comb diet (e.g. $\mathrm{Ca}, \mathrm{Mg}, \mathrm{K}$, vitamin $\mathrm{C}$ ) have been individually shown to have important roles in bone health (StendigLindberg et al. 1993; Sebastian et al. 1994; for review, see Institute of Medicine, 1997; New et al. 1997, 2000; Hall \& Greendale, 1998; Tucker et al. 1999; Morton et al. 2001; Sellmeyer et al. 2002). In support of this contention, a recent preliminary report of an ancillary study to the DASH-Sodium trial has shown that in comparison with the DASH control diet (a typical Western-type diet), consumption of the DASH Comb diet for $30 \mathrm{~d}$ reduced the levels of biochemical markers of bone formation (serum osteocalcin) and bone resorption (serum C-terminal telopeptide of type I collagen) at each of three dietary $\mathrm{Na}$ intake levels (low, intermediate and high) in adult men and women (Lin et al. 2001). These findings suggest that the DASH Comb diet may reduce the rate of bone turnover, which in turn, may lower risk of fracture by maximizing development of peak bone mass in young adults and slowing the rate of bone loss in later life (Cashman, 2002). Interestingly, the reduction in the rate of bone turnover arising from consumption of the DASH Comb diet was found in all participants, regardless of age, gender and hypertension status (Lin et al. 2001), suggesting a possible beneficial impact of this diet on bone health in normotensive and hypertensive individuals of several population subgroups.

The objective of the present study was to investigate the effect of the nutrient profiles of the three diets used in the original DASH study (namely, control, high fruit and vegetable (F/V), and Comb diets; Appel et al. 1997) on blood pressure and bone metabolism and composition in spontaneously hypertensive and normotensive adult rats.

\section{Materials and methods \\ Preparation of rat diets}

Three semipurified diets, namely control, F/V and Comb diet were used in the present study (Tables 1-3). These were based on the AIN-93M diet (that recommended for adult rats by the American Institute of Nutrition (Reeves et al. 1993)), but modified to allow the nutrient profile to reflect those reported for each of the three diets used in the DASH trial (Karanja et al. 1999). The nutrient profiles of the control, F/V and Comb diets in the present study were formulated by expressing the content of each nutrient in the three DASH diets (as described by Karanja et al. 1999) as a percentage of the related US recommended dietary allowances for these nutrients (see Table 4; National Research Council, 1989) and then adjusting the nutrient contents of the AIN-93M by similar percentages (see Tables 1-3). This produced similar percentage differences between nutrients in the three human diets (i.e. the DASH diets) and the three rodent diets used in the present study. The potential renal acid load of each of the three rodent diets was estimated using the nutrient composition data of the diets and the calculation model of Remer \& Manz (1995), which was derived for the prediction of the effects of diets on the acidity of urine in human subjects. The estimated potential renal acid load for the control, $\mathrm{F} / \mathrm{V}$ and Comb diets used in the present study were 86, -44 and $-41 \mathrm{mEq} / \mathrm{kg}$ diet, respectively.

Table 1. Composition $(\mathrm{g} / \mathrm{kg})$ of the control, high fruit and vegetable (F/V) and combination (Comb) diets

\begin{tabular}{|c|c|c|c|}
\hline $\begin{array}{l}\text { Diet ... } \\
\text { Ingredient }\end{array}$ & Control & $\mathrm{F} / \mathrm{V}$ & Comb \\
\hline Maizestarch* & $599 \cdot 717$ & $555 \cdot 808$ & $558 \cdot 779$ \\
\hline Casein & $140 \cdot 000$ & $129 \cdot 750$ & $151 \cdot 351$ \\
\hline Sucrose & $120 \cdot 250$ & $112 \cdot 141$ & 95.495 \\
\hline Fibre & $36 \cdot 110$ & $90 \cdot 102$ & 85.081 \\
\hline Oil mix* & 49.300 & $45 \cdot 690$ & 32.441 \\
\hline Modified AIN mineral mix & 35.000 & 32.437 & 31.532 \\
\hline Modified AIN vitamin mix $\ddagger$ & $10 \cdot 000$ & $9 \cdot 268$ & 9.009 \\
\hline Calcium carbonate & $5 \cdot 361$ & $7 \cdot 642$ & 20.567 \\
\hline Potassium citrate & - & 13.083 & 7.865 \\
\hline Potassium phosphate & - & 0.500 & 3.995 \\
\hline Choline bitartrate & $2 \cdot 500$ & $2 \cdot 317$ & $2 \cdot 252$ \\
\hline L-Cystine & 1.800 & 1.668 & 1.946 \\
\hline$t$-Butylhydroquinone & 0.008 & 0.007 & 0.007 \\
\hline
\end{tabular}

${ }^{*}$ Representing control, F/V and Comb diets containing respectively $(\mathrm{g} / \mathrm{kg})$ : coconut oil, $16.5,15 \cdot 3,5 \cdot 86$, olive oil $18.8,17 \cdot 4,12 \cdot 6$, soyabean oil $14 \cdot 0$, $13.0,13.9$. These oil mixtures were designed to provide diets that contained saturated, monounsaturated and polyunsaturated fatty acids in the same proportions as the three Dietary Approaches to Stop Hypertension diets (see Karanja et al. 1999).

†For the composition of mineral mixtures used in the three diets see Table 2. $\neq$ For the composition of vitamin mixtures used in the three diets see Table 3 . 
Table 2. Composition ( $\mathrm{g} / \mathrm{kg}$ mineral mix) of modified AIN 93-M mineral mixtures used in the control, high fruit and vegetable (F/V) and combination (Comb) diets

\begin{tabular}{lrcc}
\hline Diet ... & Control & F/V & Comb \\
Ingredient & & & \\
\hline Sucrose & $410 \cdot 24000$ & 418.09800 & 307.24500 \\
Potassium phosphate & 300.78000 & 427.33000 & 517.06000 \\
Calcium phosphate & 111.11000 & - & - \\
Sodium chloride & 74.00000 & 74.00000 & 74.00000 \\
Potassium sulfate & 46.60000 & 46.60000 & 46.60000 \\
Magnesium oxide & 14.04000 & 32.56000 & $36 \cdot 68000$ \\
Potassium citrate & 28.00000 & - & - \\
Ferric citrate & 11.75000 & 12.96000 & 14.48000 \\
Zinc carbonate & 1.04000 & 1.28700 & 1.33000 \\
Sodium meta-silicate & 1.08300 & 1.08300 & 1.08300 \\
$\quad$ hydrate & & & \\
Manganous carbonate & 0.63000 & 0.63000 & 0.63000 \\
Cupric carbonate & 0.18750 & 0.35600 & 0.35600 \\
Chromium potassium & 0.27500 & 0.27500 & 0.27500 \\
$\quad$ sulfate & & & \\
Boric acid & 0.08150 & 0.08150 & 0.08150 \\
Nickel chloride & 0.06370 & 0.06370 & 0.06370 \\
Sodium fluoride & 0.06350 & 0.06350 & 0.06350 \\
Lithium chloride & 0.01740 & 0.01740 & 0.01740 \\
Potassium iodate & 0.01000 & 0.01000 & 0.01000 \\
Sodium selenate & 0.01025 & 0.01025 & 0.01025 \\
Ammonium molybdate & 0.00795 & 0.00795 & 0.00795 \\
Ammonium vanadate & 0.00660 & 0.00660 & 0.00660 \\
\hline
\end{tabular}

\section{Experimental design}

Sixty male rats, 14 weeks old (n 30, Wistar-Kyoto/NHsd (WKY) strain; $n$ 30, Spontaneously Hypertensive/NHsd (SHR) strain; average weight $308 \mathrm{~g}$ for SHR rats and $286 \mathrm{~g}$ for WKY rats), were obtained from Harlan UK Ltd
Table 3. Composition ( $\mathrm{g} / \mathrm{kg}$ vitamin mix) of the modified AIN 93-M vitamin mixtures used in the control, high fruit and vegetable (F/V) and combination (Comb) diets

\begin{tabular}{lrrr}
\hline $\begin{array}{l}\text { Diet ... } \\
\text { Ingredient }\end{array}$ & Control & F/V & Comb \\
\hline Sucrose & 916.8950 & $838 \cdot 2770$ & $780 \cdot 1870$ \\
Ascorbic acid & 54.1360 & $125 \cdot 8000$ & 178.3000 \\
$\alpha$-Tocopherol acetate & 13.6500 & 18.4500 & 22.5000 \\
Cyanocobalamin & 4.6250 & 4.7500 & 6.1250 \\
Nicotinic acid & 4.5780 & 4.4200 & 4.1040 \\
Retinyl palmitate & 1.7550 & 3.5560 & 4.0096 \\
Calcium pantothenate & 1.6000 & 1.6000 & 1.6000 \\
Pyridoxine hydrochloride & 0.6300 & 1.0850 & 0.9450 \\
Thiamine hydrochloride & 0.9198 & 0.7980 & 0.6798 \\
Riboflavin & 0.6348 & 0.5290 & 0.7764 \\
Folic acid & 0.2070 & 0.3900 & 0.4280 \\
Cholecalciferol & 0.2500 & 0.2500 & 0.2500 \\
D-Biotin & 0.0200 & 0.0200 & 0.0200 \\
Phylloquinone & 0.0750 & 0.0750 & 0.0750 \\
\hline
\end{tabular}

(Bicester, Oxon., UK). All rats were fed ad libitum on a semipurified control diet (see earlier) for 1 week until they were aged 15 weeks. At this stage, both normotensive (WKY) and hypertensive (SHR) rats were separately randomized by weight into three groups of ten rats each (i.e. three groups of normotensive and three groups of hypertensive rats). One group from each strain was given the control diet while the other two groups were fed the F/V and Comb diets respectively (see earlier). Food intake of all three dietary groups in both strains was monitored for 1 week to establish whether dietary preferences between the three diets existed. To assure equivalent food consumption and avoid differences in body-weight

Table 4. Nutrient profiles of the three Dietary Approaches to Stop Hypertension (DASH) diets expressed in absolute terms and as a percentage of the recommended dietary allowances provided by each $\operatorname{diet}^{*} \dagger$

\begin{tabular}{|c|c|c|c|c|c|c|}
\hline \multirow{2}{*}{$\begin{array}{l}\text { Diet ... } \\
\text { Nutrient }\end{array}$} & \multicolumn{2}{|c|}{ Control } & \multicolumn{2}{|c|}{$\mathrm{F} / \mathrm{V}$} & \multicolumn{2}{|c|}{ Comb } \\
\hline & Absolute value & $\% \operatorname{RDA} \ddagger$ & Absolute value & $\% \operatorname{RDA\ddagger }$ & Absolute value & $\%$ RDA \\
\hline Protein (g) & $97 \cdot 5$ & 144 & 97.5 & 144 & 117 & 186 \\
\hline Fat $(g)$ & 107 & 123 & 107 & 123 & 78 & 90 \\
\hline Carbohydrate (g) & 325 & 110 & 338 & 115 & 384 & 130 \\
\hline Fibre§ (g) & 13 & 72 & 35 & 194 & 34 & 189 \\
\hline Vitamin C (mg) & 145 & 181 & 231 & 289 & 294 & 367 \\
\hline Vitamin E (mg tocopherol units) & $9 \cdot 1$ & 91 & $12 \cdot 3$ & 123 & $15 \cdot 0$ & 150 \\
\hline Vitamin $B_{12}(\mu \mathrm{g})$ & 3.7 & 185 & 3.8 & 190 & 4.9 & 245 \\
\hline Niacin (mg niacin equivalents) & 29 & 153 & 28 & 147 & 26 & 137 \\
\hline Vitamin A & 2215 & 219 & 4499 & 444 & 5062 & 501 \\
\hline Vitamin $B_{6}(\mathrm{mg})$ & 1.8 & 90 & 1.5 & 155 & $2 \cdot 2$ & 135 \\
\hline Thiamin (mg) & $2 \cdot 3$ & 153 & 2.0 & 133 & $1 \cdot 7$ & 113 \\
\hline Riboflavin (mg) & 1.8 & 106 & 1.5 & 88 & $2 \cdot 2$ & 129 \\
\hline Folic acid $(\mu \mathrm{g})$ & 207 & 103 & 390 & 195 & 428 & 214 \\
\hline Calcium (mg) & 527 & 66 & 528 & 66 & 1462 & 183 \\
\hline Magnesium (mg) & 205 & 58 & 475 & 136 & 535 & 153 \\
\hline Phosphorus (mg) & 1144 & 143 & 1177 & 147 & 1690 & 211 \\
\hline Potassium (mg) & 2051 & 114 & 5067 & 281 & 5181 & 289 \\
\hline Iron (mg) & $19 \cdot 4$ & 194 & 21.4 & 214 & 23.9 & 239 \\
\hline Copper (mg) & 1.0 & 62 & 1.9 & 119 & 1.9 & 119 \\
\hline Zinc (mg) & 9.5 & 63 & $11 \cdot 7$ & 78 & $12 \cdot 1$ & 81 \\
\hline
\end{tabular}

F/V; fruit and vegetable; Comb, combination.

* For details of DASH diets, see Karanja et al. (1999).

† Based on the US recommended dietary allowance values (National Research Council, 1989).

$\ddagger$ Content per $10.88 \mathrm{MJ}(2600 \mathrm{kcal})$ diet (Karanja et al. 1999).

$\S$ Fibre recommendation was based on those of the Department of Health (1991). 
gain among the dietary groups during the intervention period, an equalized feeding paradigm was used. The amount of food offered to all rats within a strain was limited to the ad libitum food intake (adjusted for the energy content of the diets) of the group that ate the least amount of food during the initial 1 week food-intake monitoring period. All animals were given distilled water ad libitum for the duration of the study. Rats were housed individually and feed was provided at 10.00 hours each day. Blood pressure of each animal was measured at baseline, week 4 and week 8 of the dietary intervention study. During the last week of the study, all rats were placed in individual metabolism cages with a grid floor and a facility for separate collection of faeces and urine.

Urine samples $(24 \mathrm{~h})$ were collected for each animal over the last $2 \mathrm{~d}$ of the study in vessels covered with $\mathrm{Al}$ foil to prevent degradation by light of the pyridinium crosslinks. The urine samples for each animal were pooled and the volumes recorded. Portions of the pooled urine samples were acidified with $12 \mathrm{M}-\mathrm{HCl}(2250 \mu \mathrm{l} / \mathrm{l}$ urine $)$ and stored at $-20^{\circ} \mathrm{C}$ until required for analysis.

After $56 \mathrm{~d}$ on their respective diets, all animals were anaesthetized with diethyl ether and blood was drawn from the heart into vacutainer tubes, processed to serum, and immediately stored at $-80^{\circ} \mathrm{C}$ until required. Final body weights were recorded and femora were harvested. Femora were cleaned of adhering soft tissue, and stored in sealed containers at $-20^{\circ} \mathrm{C}$ until required for determination of physical properties and macromineral content.

\section{Experimental techniques}

Blood pressure. Systolic blood pressure measurements were recorded by a non-invasive computerized rat-tail cuff blood pressure system (RTBP1007 rat-tail blood pressure system; Kent Scientific, Litchfield, CT, USA), connected to a MacLab database acquisition system (AD Instruments Ltd., NSW, Australia). Briefly, arterial pulsation was detected with a piezoelectric sensor attached to the rat tails. Using an occlusion air cuff placed upstream of the sensor, arterial blood flow was stopped. The pressure inside the cuff was then progressively released. When the pressure inside the cuff became analogous to the systolic blood pressure, the blood was allowed to flow again in the tail artery. At this point, the cuff pressure was recorded. Prior to the experimental days, rats were accustomed to the experimental process; rats were maintained in the restrained chamber for $15 \mathrm{~min}$ on two consecutive days before any blood pressure measurement. This process was shown to reduce animal stress during experiments. On the experimental day, rats were first placed in a restraining chamber, maintained at $37^{\circ} \mathrm{C}$, where they were allowed to rest for $5 \mathrm{~min}$. The cuff and the sensor were then placed around the tail of the rat and five measurements were performed per rat. The five values were averaged, resulting in daily blood pressure values. It is important to note that the five values for a given day were only kept as a result when they showed relative constancy. For example, stressed animals demonstrated, during the same day, high variability in their measured blood pressure values; therefore, only values within the same range of $\pm 15 \mathrm{mmHg}$ were considered for further calculations. The contribution of unreliable results due to animal stress to any final data was thus minimized.

Urinary pyridinoline and deoxypyridinoline. Pooled urine samples were analysed in duplicate using an automated analysis system (Gilson ASPEC (Automated Sample Preparation with Extraction Columns); Gilson S.A., Villiers-le-Bel, France) linked directly to a gradient HPLC system comprising a Gilson 321 pump and a Shimadzu RF-10AxL fluorescence detector (Shimadzu Scientific Instruments Inc., Colombia, MD, USA). In brief, portions of pooled urine $(250 \mu \mathrm{l})$ were first hydrolysed with an equal volume of $12 \mathrm{M}-\mathrm{HCL}$ at $107^{\circ} \mathrm{C}$ for $18 \mathrm{~h}$. The crosslinks from urine hydrolysates where then extracted with cellulose partition chromatography, with the use of an internal standard (acetylated pyridinoline (pyr); MetraBiosystems Ltd, Wheatley, Oxon., UK) (Pratt et al. 1992). The acetylated Pyr was used in accordance with the method described by Calabresi et al. (1994) and Robins et al. (1994). The crosslinks contents of urine samples were quantified by external standardization using a commercially available Pyr-deoxypyridinoline (Dpyr) HPLC calibrator (MetraBiosystems Ltd). The intra-assay $\mathrm{CV}$ for Pyr and Dpyr measured as the variation between ten chromatograms obtained between column regenerations as described by Colwell et al. (1993) were 5 and $3 \%$ respectively. The inter-assay CV for Pyr and Dpyr were 9 and $11 \%$ respectively.

Urinary and serum creatinine levels. Urinary and serum creatinine were measured in duplicate by a colourimetric procedure using a diagnostic kit (catalogue no. 555A; Sigma Diagnostics, St Louis, MO, USA). Intraand inter-assay CV were 3.6 and $7.9 \%$ respectively.

Femoral calcium, phosphorus and magnesium levels. Weighed femora (dried overnight at $110^{\circ} \mathrm{C}$ ) were dry ashed at $600^{\circ} \mathrm{C}$ for $16 \mathrm{~h}$ as described by Hoshino et al. (1998), and the ash content was calculated by weight loss on a dry basis. The ash was digested with $16 \mathrm{M}-\mathrm{HNO}_{3}$. $\mathrm{Ca}$ and $\mathrm{Mg}$ were analysed in duplicate in femoral digests by atomic absorption spectrophotometry (Pye-Unicam Atomic Absorption Spectrophotometer, Model SP9; PyeUnicam, Cambridge, Cambs., UK) after appropriate dilution with $\mathrm{LaCl}_{3}$ solution $(5 \mathrm{~g} / 1$; $\mathrm{BDH}$ Ltd, Poole, Dorset, UK). A range of $\mathrm{Ca}$ and $\mathrm{Mg}$ standards were used to obtain $\mathrm{Ca}$ and $\mathrm{Mg}$ calibration curves. The intra- and inter-assay $\mathrm{CV}$ for $\mathrm{Ca}$ were 2.8 and $7.8 \%$, and for $\mathrm{Mg}$ were 3.2 and $8.8 \%$ respectively. $\mathrm{P}$ was determined in the femoral digests by the method of Weissman \& Pileggi (1974). The intra- and inter-assay CV for P were 4.2 and $6.1 \%$ respectively. The accuracy of mineral analysis was assured in each analytical run by appropriate recovery of mineral in dry-ashed samples of National Institute of Standards and Technology-certified bone meal (Standard Reference Material 1486; Laboratory of the Government Chemist, Teddington, Middlesex, UK).

Femoral mass, length, volume and density. The length of each right femur was measured with a vernier caliper. The width of the femur (at the midpoint between epiphyses) was also measured with a vernier caliper. Bone volume and density were measured by Archimedes' principle (Kalu et al. 1991). Briefly, each bone was cut at 
the mid-diaphysis and the marrow was washed out. Then each bone was put in an unstoppered vial filled with distilled water, and the vial was placed under a vacuum for $90 \mathrm{~min}$ to ensure that all the trapped air diffused out of the bone. Each bone was removed from its vial, blotted with gauze, weighed and returned to the vial containing distilled water. The bone was re-weighed in a boat suspended, but completely immersed, in water previously equilibrated to room temperature, and the density $\left(\mathrm{g} / \mathrm{cm}^{3}\right.$ bone volume) was calculated. Bone mass was expressed in terms of the dry weight, and bone density as the dry weight per unit volume. Bone mineral mass was taken as the ash weight per bone length.

Serum osteocalcin levels. Serum osteocalcin concentrations were measured in duplicate using the Rat-MID osteocalcin ELISA (Osteometer Biotech A/S, Herlev, Denmark). The intra- and inter-assay CV were 4.0 and $6.6 \%$ respectively.

\section{Statistical analysis}

Before the start of the experiment, the required sample size at $\alpha 0.05$ and $\beta 0.80$ was calculated (Dallal, 1990) using the variability around the mean biomarker levels in rats and a selected minimum detectable percentage difference (i.e. $\Delta$ ) in bone biomarker levels among groups of $15 \%$. A value of $15 \%$ was chosen as a meaningful difference in the absence of reported data on the magnitude of the reduction in bone biomarker levels following the DASH Comb diet (Lin et al. 2001). Statistical analysis of the data was performed using DataDesk ${ }^{\circledR}$ (version 6.0; Data Description Inc., Ithaca, NY, USA). Data for all variables was normally distributed and allowed for parametric tests of significance. Results are presented as mean values with their pooled standard errors. Where appropriate, data were subjected to two-way ANOVA, with variation attributed to diet and rat strain (Snedecor \& Cochran, 1967). Where significant $(P<0.05)$ differences (i.e. either an effect of diet, rat strain or an interaction between the two) were found, Fisher's least significant difference test was used to perform post hoc comparison of all pairs of means (Snedecor \& Cochran, 1967). To test the effect of either diet or strain alone, data was subject to one-way ANOVA, and where significant $(P<0.05)$ differences (i.e. an independent effect of diet or rat strain) were found, Fisher's least significant difference test was used to perform post hoc comparison of all pairs of means (Snedecor \& Cochran, 1967). In addition, the effect of rat strain on urinary pyridinium crosslink excretion was also assessed by ANOVA after the urinary crosslink values had been adjusted for creatinine clearance rates.

\section{Results}

Mean body-weight gain did not differ significantly among dietary groups in either the SHR or WKY rats (Fig. 1). SHR rats were significantly $(P<0.01)$ heavier than WKY rats at all time points of the intervention. This was particularly evident at the beginning of the 8-week dietary intervention period, but there appeared to be a convergence of body weights between the two strains over time.

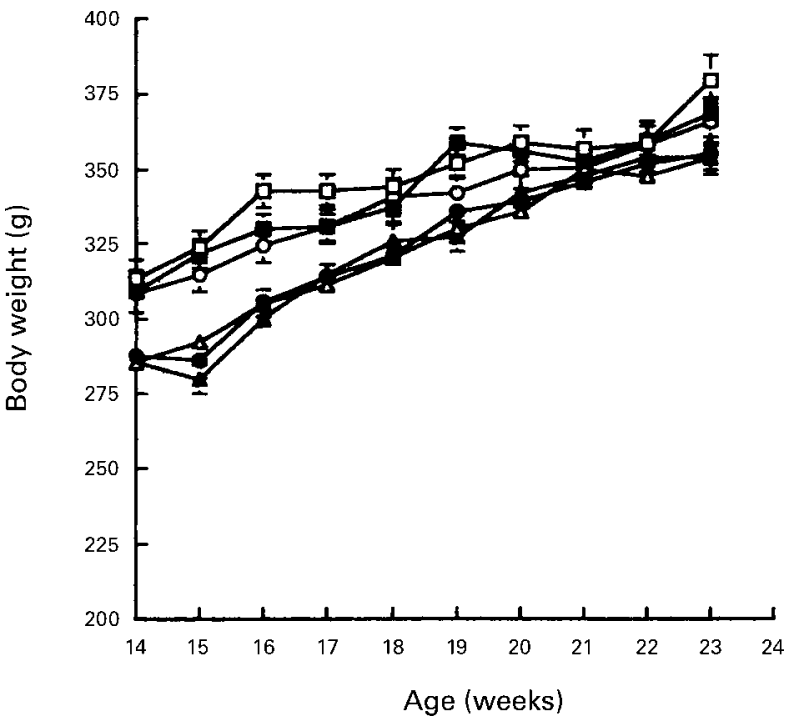

Fig. 1. Body weights over time in normotensive (WKY) and spontaneously hypertensive (SHR) rats fed on the control, high fruit and vegetable (F/V) and high fruit and vegetable and low-fat dairy produce (Comb) diets. Groups were: $(\square)$, control diet (SHR rats); ( $\mathbf{\square})$ F/V diet (SHR rats); (O) Comb diet (SHR); (•) control diet (WKY rats); $(\triangle)$, F/V diet (WKY rats); $(\mathbf{\Delta})$, Comb diet (WKY rats). For details of diets and procedures, see Tables $1-3$ and p. 714, 715 . Values are means with their standard errors shown by vertical bars for ten rats per group. SHR rats were significantly heavier $(P<0.01)$ than WKY rats at all time points. There were no significant differences $(P>0.05)$ in body weight between dietary groups within a strain.

The effect of rat strain and diet on blood pressure is shown in Table 5. As expected, blood pressure was significantly $(P<0.0001)$ greater in the SHR rats than WKY rats at baseline, week 4 and week 8 of the dietary intervention period. There was no effect of dietary treatment on blood pressure at any time point, irrespective of strain.

The effect of rat strain and dietary treatment on physical properties (length, width, dry weight, ash and density) and macronutrient content ( $\mathrm{Ca}, \mathrm{Mg}, \mathrm{P}$ and bone mineral mass) of femora is shown in Table 6 . All of the physical variables, with the exception of bone density $(P>0.05)$, were significantly $(P<0.0001)$ greater in SHR rats compared with WKY rats. In addition, when femoral dry weight and ash weight were expressed relative to body weight, these variables were still significantly $(P<0 \cdot 0001)$ greater in SHR rats than WKY rats. There was no effect of dietary treatment on length, width, dry weight, ash weight and density, irrespective of strain.

The concentration $(\mathrm{mg} / \mathrm{g}$ bone) of $\mathrm{Ca}$ and $\mathrm{P}$ in femora was unaffected by rat strain. However, when the femoral $\mathrm{Ca}$ and $\mathrm{P}$ were expressed as content (mg/bone), SHR rats had significantly $(P<0 \cdot 0001)$ greater $\mathrm{Ca}$ and $\mathrm{P}$ than WKY rats. Neither the content nor concentration of $\mathrm{Ca}$ or $\mathrm{P}$ was affected by diet, irrespective of strain. While femoral $\mathrm{Mg}$ concentration was significantly $(P<0 \cdot 0001)$ lower in the SHR rats compared with the WKY rats, femoral $\mathrm{Mg}$ content (mg/bone) was significantly $(P<0.001)$ greater in SHR rats than WKY rats. Two-way ANOVA showed that femoral $\mathrm{Mg}$ concentration was affected $(P<0 \cdot 05)$ by diet. Post hoc analysis showed that SHR rats fed the $\mathrm{F} / \mathrm{V}$ diet had significantly $(P<0.01)$ 
Table 5. Blood pressure of adult male normotensive and spontaneously hypertensive rats fed the control, high fruit and vegetable (F/V) and combination (Comb) diets*

(Mean values with their pooled standard errors for ten rats per group)

\begin{tabular}{|c|c|c|c|c|c|c|c|c|c|c|}
\hline \multirow{2}{*}{$\begin{array}{l}\text { Rat strain...... } \\
\text { Dietary treatment... }\end{array}$} & \multicolumn{3}{|c|}{ Hypertensive rats } & \multicolumn{3}{|c|}{ Normotensive rats } & \multirow[b]{2}{*}{ Pooled SEM } & \multicolumn{3}{|c|}{$\begin{array}{c}\text { Statistical significance of variance } \\
\text { ratio }(P)\end{array}$} \\
\hline & Control & $\mathrm{F} / \mathrm{V}$ & Comb & Control & $\mathrm{F} / \mathrm{V}$ & Comb & & Strain & Diet & Strain $\times$ Diet \\
\hline \multicolumn{11}{|c|}{ Blood pressure (mmHg) } \\
\hline Baseline & 181 & 178 & 176 & 127 & 127 & 128 & 4 & $<0.0001$ & 0.856 & $0 \cdot 727$ \\
\hline Week 4 & 176 & 180 & 177 & 130 & 128 & 130 & 2 & $<0.0001$ & 0.887 & 0.317 \\
\hline Week 8 & 176 & 179 & 178 & 130 & 129 & 125 & 3 & $<0.0001$ & 0.538 & 0.450 \\
\hline
\end{tabular}

${ }^{*}$ For details of diets and procedures see Tables $1-3$ and p. $714,715$.

higher femoral Mg concentration compared with SHR rats fed the control or Comb diets. Femoral Mg content was unaffected by diet, irrespective of strain. Bone mineral mass was significantly $(P<0 \cdot 0001)$ higher in SHR rats compared with that in WKY rats. Bone mineral mass was unaffected by diet, irrespective of strain.

The effects of rat strain and dietary treatment on creatinine clearance and biochemical markers of bone resorption (urinary Pyr and Dpyr) and bone formation (serum osteocalcin) are shown in Table 7. Daily creatinine output in urine was significantly $(P<0.05)$ lower in SHR than WKY rats. Serum creatinine concentrations tended $(P=0.052)$ to be greater in SHR rats than WKY rats. Creatinine clearance was significantly $(P<0.05)$ lower in SHR rats than in WKY rats. Urinary and serum creatinine and creatinine clearance was unaffected by diet, irrespective of strain. Urinary Pyr and Dpyr excretion (expressed as daily output) was similar in SHR and WKY rats. In addition, urinary crosslink excretion (adjusted for creatinine clearance rates) was similar in SHR and WKY rats. Urinary Pyr and Dpyr excretion was significantly $(P<0.05)$ lower in SHR rats fed the combination diet than that in SHR rats given the F/V and control diets. On the other hand, urinary Pyr and Dpyr excretion in WKY rats was unaffected by diet.

In the present study, serum osteocalcin was unaffected by rat strain (Table 7). Serum osteocalcin was affected $(P<0.05)$ by diet. There was, however, a significant $(P<0.05)$ interaction between rat strain and diet. Post hoc analysis showed that SHR rats fed the Comb diet had significantly $(P<0.05)$ lower serum osteocalcin than SHR rats given the F/V and control diets. Serum osteocalcin in WKY was unaffected by diet.

\section{Discussion}

Effect of dietary intervention to stop hypertension-type diet on blood pressure

In the present study, SHR rats were heavier than WKY rats, in agreement with the findings of several other studies (Schedl et al. 1984; Hatton et al. 1989; Pörsti, 1992). However, other studies have reported that WKY rats were heavier than SHR rats (Lau et al. 1984; Izawa et al. 1985; Galletti et al. 1991; Touyz \& Milne, 1999; Pezeshk \& Dalhouse, 2000; Vasedv et al. 2000). The reasons for this discrepancy between studies are not clear. In the present study, as expected, SHR rats had significantly elevated blood pressure relative to WKY rats. Blood pressure of the SHR and WKY animals (which were aged 15 weeks at the beginning of the dietary intervention) did not change over the 8-week supplementation period. This is in agreement with the findings of some studies which have used similarly aged normotensive and hypertensive rats (Yoshioka et al. 1985; Sato et al. 1995; Vasdev et al. 2000); however, increased blood pressure development over time in similarly aged SHR rats has been noted in some studies (Tolavnen et al. 1998; Newaz et al. 1999; Touyz \& Milne, 1999). In the present study, dietary provision of the nutrient profiles of the DASH-type diets (Karanja et al. 1999) over an 8-week period had no effect on blood pressure of male SHR or WKY rats. This is in contrast to the reductions in blood pressure seen in human subjects, with high-normal to mildly elevated blood pressure, that were given either the DASH F/V or Comb diet for 8 weeks (Appel et al. 1997; Moore et al. 2001). Several previous studies in hypertensive rats have shown a beneficial blood pressure-lowering effect of diets supplemented with one or two individual nutrients, such as Ca (McCarron et al. 1981; Blakeborough et al. 1990; Pörsti, 1992; Mäkynen et al. 1995), Mg (Touyz \& Milne, 1999), K (Tolvanen et al. 1998), vitamin E (Pezehhk \& Dalhouse, 2000; Chen et al. 2001) or vitamin C (Chen et al. 2001). For example, McCarron et al. (1981) reported that $\mathrm{Ca}$ supplementation of the diet of 10 -week-old male SHR rats attenuated the development of hypertension in these animals. Pörsti (1992) also found that $\mathrm{Ca}$ supplementation of 8-week-old male rats attenuated the development of blood pressure in SHR rats, but had no effect in WKY rats. Mäkynen et al. (1995) reported that $\mathrm{Ca}$ supplementation, either alone or in combination with $\mathrm{Mg}$, of 8-week-old rats, attenuated the development of blood pressure in SHR rats, whereas Mg supplementation alone had no effect on blood pressure in SHR rats. Blood pressure in normotensive animals was unaffected by $\mathrm{Ca}$, $\mathrm{Mg}$ or combined $\mathrm{Ca}$ and $\mathrm{Mg}$ supplementation (Mäkynen et al. 1995). Tolvanen et al. (1998) reported that both Ca and $\mathrm{K}$ supplementation markedly lowered blood pressure development in 7-week-old SHR rats, with their combined supplementation reducing blood pressure even further.

There are several possible reasons for the lack of antihypertensive effect of increased $\mathrm{Ca}, \mathrm{Mg}, \mathrm{K}$ and vitamin intake (provided by the F/V and Comb diets) in SHR rats used in the present study. In the present study, the intake 
Diet, blood pressure and rat bone

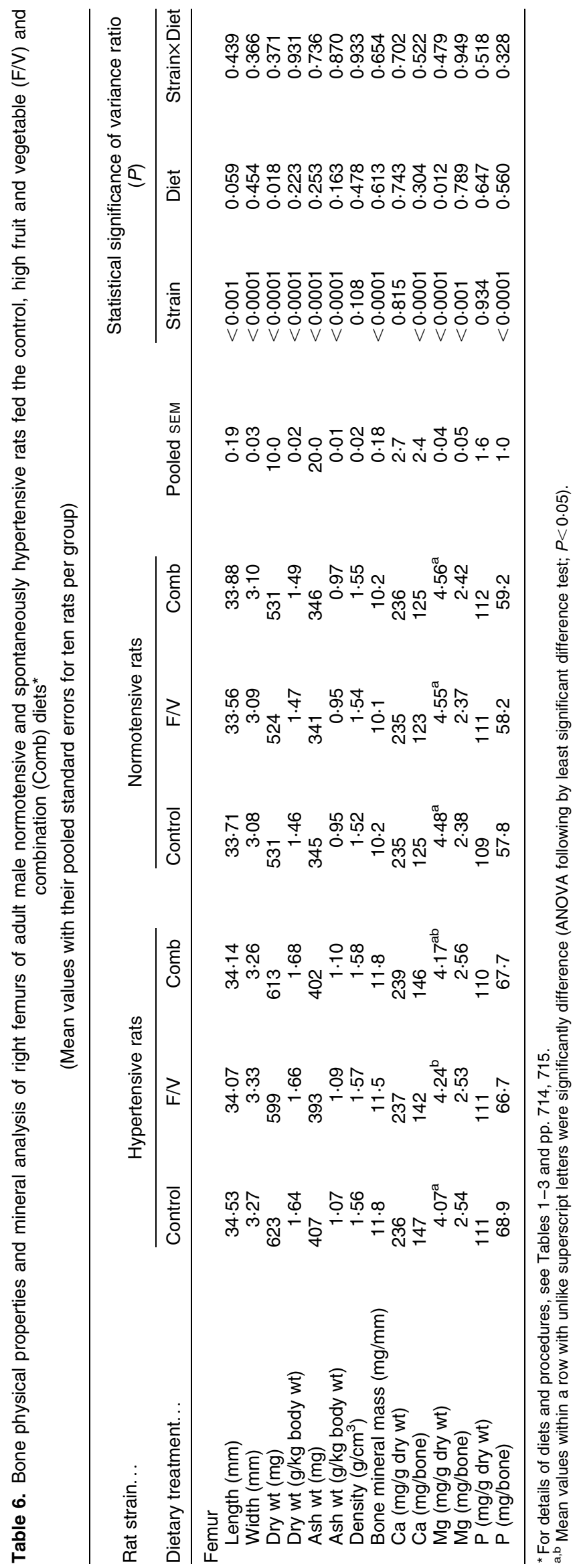


of twenty nutrients and/or dietary components were altered (which could have lead to several nutrient-nutrient interactions), whereas in the studies mentioned earlier the intake of only one or two nutrients was increased (McCarron et al. 1981; Blakeborough et al. 1990; Pörsti, 1992; Mäkynen et al. 1995; Tolvanen et al. 1998; Touyz \& Milne, 1999; Pezehhk \& Dalhouse, 2000; Chen et al. 2001). In addition, the greatest increment in dietary $\mathrm{Ca}$ content between the three diets used in the present study was from 3.3 to $9 \cdot 1 \mathrm{~g} / \mathrm{kg}$ diet, whereas the minimum level of $\mathrm{Ca}$ supplementation above the recommended level $(5 \mathrm{~g} \mathrm{Ca} / \mathrm{kg}$ diet; that recommended for adult rats by the American Institute of Nutrition (Reeves et al. 1993)) that produced a blood pressure-lowering effect in previously reported studies was $20 \mathrm{~g} \mathrm{Ca} / \mathrm{kg}$ diet (Lewanczuk et al. 1990; Rao et al. 1994). In the present study, the greatest increment in dietary $\mathrm{K}$ content between the three diets was from 4.0 to $10.4 \mathrm{~g} / \mathrm{kg}$ diet, whereas in previous studies, the level of $\mathrm{K}$ supplementation which led to a significant reduction in blood pressure in hypertensive rats was $35 \mathrm{~g} / \mathrm{kg}$ diet (Tolvanen et al. 1998; Wu et al. 1998). Similarly, in the present study, the dietary vitamin C and E contents were increased from 541 to $1783 \mathrm{mg} / \mathrm{kg}$ diet, and from $30.9 \mathrm{mg} / \mathrm{kg}$ diet to $51.4 \mathrm{mg} / \mathrm{kg}$ diet respectively. These dietary levels are far below the amounts which have been shown in previous studies to produce a significant reduction in blood pressure in SHR rats (Pezehhk \& Dalhouse, 2000; Chen et al. 2001).

The increments in various nutrient contents in the $\mathrm{F} / \mathrm{V}$ and Comb diets used in the present study were designed to reflect those in the two equivalent DASH study diets (Karanja et al. 1999), and consequently were not as great as those used in previous studies of hypertensive animals (McCarron et al. 1981; Blakeborough et al. 1990; Pörsti, 1992; Mäkynen et al. 1995; Tolvanen et al. 1998; Touyz \& Milne, 1999; Pezehhk \& Dalhouse, 2000; Chen et al. 2001). Furthermore, in keeping with the DASH study design, the diets in the present study were fed to the normotensive and hypertensive animals for 8 weeks. This time-scale of dietary intervention is shorter than that used in previous rat studies (in the range 10-38 weeks) investigating the blood pressure-lowering potential of various nutrients (McCarron et al. 1981; Blakeborough et al. 1990). In addition, the age of the animals at initiation of the dietary intervention may modulate the impact of a certain nutrient(s) on blood pressure regulation in hypertensive rats. For example, McCarron et al. (1981) found that Ca supplementation of male SHR rats from age 10 to 34 weeks had no significant effect on blood pressure, whereas continued $\mathrm{Ca}$ supplementation from age 34 to 48 weeks lead to a significant $(P<0.0001)$ attenuation of blood pressure elevation. Mäkynen et al. (1995) reported that divergence in blood pressure between Ca-supplemented and -unsupplemented SHR rats (beginning at age 8 weeks) was only significant at 22 weeks of age. On the other hand, Touyz \& Milne (1999) have suggested that, in terms of blood pressure regulation, younger rats (aged 6-14 weeks) respond to $\mathrm{Mg}$ supplementation or deprivation, whereas adult rats (aged 16-18 weeks) do not. Therefore, the dietary interventions in the present study may either not have been of sufficient length, or were 
not begun early enough in the development of hypertension, to lead to a significant reduction in blood pressure in SHR rats.

\section{Proposed link between hypertension and osteoporosis}

As mentioned previously, hypertension has been associated with abnormalities of $\mathrm{Ca}$ and bone metabolism in human subjects (McCarron et al. 1980; Cappuccio et al. 1999, 2000) and rats (McCarron et al. 1981, 1985; Pörsti, 1992). Moreover, MacGregor \& Cappuccio (1993) have hypothesized that the calciuria in hypertensive patients is compensated not by increased intestinal absorption of $\mathrm{Ca}$, but by that liberated by resorption of bone, and that hypertensive patients are thus more prone to bone demineralization, bone fracture and osteoporosis. In support of this contention, bone mineral density among hypertensive subjects has been reported as being lower than that of normotensive subjects (Metz et al. 1999; Tsuda et al. 2001). Furthermore, the temporal sequence whereby high blood pressure precedes and predicts the loss of bone mineral has now been established in a large prospective study of 3676 white postmenopausal women (Cappuccio et al. 1999).

\section{Effect of Dietary Intervention to stop hypertension-type diet on bone metabolism and mass}

In light of the proposed link between hypertension and osteopenia (MacGregor \& Cappuccio, 1993; Cappuccio et al. 2000) and the anti-hypertensive effect of the DASH diets (Appel et al. 1997, 2001; Moore et al. 1999; Conlin et al. 2000; Vollmer et al. 2001), it seemed timely to investigate whether the DASH-type diets have an osteoprotective effect. In the present study, while femoral bone mineral density and $\mathrm{Ca}$ and $\mathrm{P}$ concentrations were similar in both strains of rat, femoral length, width, dry weight, ash weight, $\mathrm{Ca}, \mathrm{Mg}$ and $\mathrm{P}$ content and bone mineral mass were greater in SHR than WKY rats. These findings are in agreement with the findings of some studies which show that SHR animals have a greater bone mass and/or macromineral content than WKY rats (Lau et al. 1984; DeMoss \& Wright, 1998; Patel et al. 2000); however, they are in contrast with the findings of other studies which show that these variables are greater in WKY rats than SHR rats (Izawa et al. 1985; Lucas et al. 1986; Wallach \& Verch, 1986; Barbagallo et al. 1990, 1991; Metz et al. 1990).

In the present study, the nutrient profiles of the DASH $\mathrm{F} / \mathrm{V}$ and Comb diets had no effect on physical properties or $\mathrm{Ca}$ and $\mathrm{P}$ content of femora in either SHR or WKY rats. While femoral $\mathrm{Mg}$ concentration was unaffected by diet in the WKY rats, it was significantly increased in SHR rats fed the F/V diet compared with that of SHR rats fed the control or Comb diets. The reasons for the increased femoral $\mathrm{Mg}$ concentration in rats fed the $\mathrm{F} / \mathrm{V}$ diet relative to those fed the Comb diet are unclear, especially as the Comb diet contained slightly more $\mathrm{Mg}$ than the $\mathrm{F} / \mathrm{V}$ diet $(782$ and $693 \mathrm{mg} \mathrm{Mg} / \mathrm{kg}$ diet respectively). However, the Comb diet also contained approximately 3-fold the $\mathrm{Ca}$ content of the F/V diet. A high-Ca diet (containing 4-fold the recommended $\mathrm{Ca}$ content,
$5 \mathrm{~g} \mathrm{Ca} / \mathrm{kg}$ diet) has been shown to lead to reduced serum and bone $\mathrm{Mg}$ levels in male rats over a 12-week period, relative to rats receiving the recommended dietary $\mathrm{Ca}$ level (Patwardhan et al. 2001). Therefore, it is possible that the high $\mathrm{Ca}$ content of the Comb diet competed with $\mathrm{Mg}$ and thus impeded its uptake into femora of SHR rats.

In the present study, the rate of bone turnover in hypertensive rats, as indicated by biochemical markers of bone resorption and bone formation, was reduced by consumption of the Comb diet over an 8-week period. On the other hand, there was no effect of diet on bone turnover in the normotensive rats. These findings in hypertensive rats support the recent preliminary findings of Lin et al. (2001) that showed that consumption of the DASH Comb diet for $30 \mathrm{~d}$ reduced the levels of biochemical markers of bone formation (serum osteocalcin) and bone resorption (serum C-terminal telopeptide of type I collagen) in adult men and women (Lin et al. 2001). The reduced rate of bone turnover in SHR rats fed the Comb diet for 8 weeks in the present study did not appear to be translated into detectable differences in bone mass or composition in these animals. However, Sinha et al. (1988) have suggested that such a relatively short dietary intervention may not be of sufficient time for measurable changes in femoral mass that would follow dietary-induced alterations in the rate of bone metabolism.

\section{Mechanism by which the dietary intervention to stop hypertension combination diet lowers bone turnover}

The mechanism by which the DASH Comb diet in the study by Lin et al. (2001) and the Comb diet in the present study reduced bone turnover is unclear. If one accepts the proposed association between hypertension, hypercalciuria and osteopenia (Cappuccio et al. 1999), then by virtue of its blood pressure-lowering effect alone, consumption of the DASH Comb diet may lead to a reduction in the rate of bone resorption. However, there was no anti-hypertensive effect of the Comb diet in SHR rats in the present study. The reduced rate of bone resorption in SHR rats fed the DASH Comb diet may be due to its low estimated potential renal acid load $(-41 \mathrm{mEq} / \mathrm{kg})$, relative to that of the control diet $(86 \mathrm{mEq} / \mathrm{kg})$, as recently suggested by New (2002). However, the F/V diet, which also had a low estimated potential renal acid load ( $-44 \mathrm{mEq} / \mathrm{kg}$ ), had no effect on the rate of bone resorption in SHR rats in the present study. It is also possible that the mechanism by which the Comb-type diet lead to reduction in bone turnover in both human subjects and rats may be independent of an effect on blood pressure, but may be due to the fact that many of the nutrients that are rich in the DASH Comb diet (e.g. $\mathrm{Ca}, \mathrm{Mg}, \mathrm{K}$, vitamin $\mathrm{C}$ ) have been individually shown to have important roles in bone health (StendigLindberg et al. 1993; Sebastian et al. 1994; for review, see Institute of Medicine, 1997; New et al. 1997, 2000; Hall \& Greendale, 1998; Tucker et al. 1999; Morton et al. 2001; Sellmeyer et al. 2002. While this would help explain the observed reduction in bone turnover in the SHR rats fed the Comb diet in the present study, despite its lack of effect on blood pressure regulation, it would not explain the lack of effect of the same diet on bone 
turnover in the normotensive rats. The SHR rats in the present study had significantly lower creatinine clearance rates relative to the WKY rats, suggesting differences in renal function between strains. Reduced creatinine clearance rates have also been noted in hypertensive patients (Catena et al. 2000; Kadiri \& Ajayi, 2000). Differences in renal function between hypertensive and normotensive animals may have some bearing on whether the Comb diet can regulate bone turnover or not. The mechanism by which the Comb diet reduces bone turnover in the face of hypertension requires further investigation.

\section{Conclusion}

The findings of the present study show that a Comb-type diet, rich in several minerals and vitamins, can reduce the rate of bone turnover in hypertensive animals. These findings in rats would suggest that in addition to benefits for blood pressure regulation and cardiovascular health, the DASH-type Comb diet could also benefit skeletal health of hypertensive individuals, but this potential benefit would need to be confirmed in studies with human subjects.

\section{References}

Allender PS, Cutler JA, Follmann D, Cappuccio FP, Pryer J \& Elliott P (1996) Dietary calcium and blood pressure: a metaanalysis of randomized clinical trials. Annals of Internal Medicine 124, 825-831.

Appel L, Moore TJ, Obarzanek E, Vollmen WM, Svetkey LP, Sacks FM, Bray GA, Vogt TM, Cutler JA, Windhauser MM, Lin P-H, Karanja N (1997) A clinical trial of the effects of dietary patterns on blood pressure. New England Journal of Medicine 336, 1117-1124.

Appel LJ, Aickin M, Conlin PR, Harsha DW, Meltesen GT, Moore TJ, Sacks FM \& Svetkey LP (2001) The effects of sodium reduction and the DASH diet on ambulatory blood pressure (ABP) in African-Americans and non-AfricanAmericans; results from the DASH-sodium feeding study. American Journal of Hypertension 14, 15A.

Appel LJ, Miller EG, Jee SH, Stolzenberg-Solomon R, Lin P-H, Erlinger T, Nadeau MR \& Selhub J (2000) Effects of dietary patterns on serum homocysteine. Results of a randomized, controlled feeding trial. Circulation 102, 852-857.

Barbagallo M, Quaini F, Baroni MC, Barbagallo CM, Boiardi L, Passeri G, Arlunno B, Delsignore R \& Passeri M (1991) Histological evidence of increased turnover in bone from spontaneously hypertensive rats. Cardioscience 2, 15-17.

Barbagallo M, Raddino R, Restori G, Boiardi L, Novo S \& Strano A (1990) Alterations of calcium metabolism in spontaneously hypertensive rats. Cardioscience 2, 105-107.

Blakeborough P, Nevelle SG \& Rolls BA (1990) The effects of diets adequate and deficient in calcium on blood pressures and activities of intestinal and kidney plasma membrane enzymes in normotensive and hypertensive rats. British Journal of Nutrition 63, 65-78.

Brickman AS, Nyby MD, von Hungen K, Eggena P \& Tuck ML (1990) Calcitropic hormones, platelet calcium and blood pressure in essential hypertension. Hypertension 16, 515-522.

Calabresi E, Lasagni L, Franceschelli F, Bartolini L \& Serio M (1994) Use of an internal standard to measure pyridinoline and deoxypyridinoline in urine (letter). Clinical Chemistry 40, 336-337.
Cappuccio FP, Kalaitzidis R, Duneclift S \& Eastwood JB (2000) Unravelling the links between calcium excretion, salt intake, hypertension, kidney stones and bone metabolism. Journal of Nephrology 13, 169-177.

Cappuccio FP, Meilahn E, Zmuda JM \& Cauley JA (1999) High blood pressure and bone-mineral loss in elderly white women. Lancet 354, 971-975.

Cashman KD (2002) Prebiotics and calcium bioavailability. In Probiotics and Prebiotics: Where are we going?, pp. 149-174 [GW Tannock, editor]. Wymondham, Norfolk: Horizon Scientific Press.

Catena C, Zingaro L, Casaccio D \& Sechi LA (2000) Abnormalities of coagulation in hypertensive patients with reduced creatinine clearance. American Journal of Medicine 109, 556-561.

Chen X, Touyz RM, Park JB \& Schiffrin EL (2001) Antioxidant effects of vitamins $\mathrm{C}$ and $\mathrm{E}$ are associated with altered activation of vascular NADPH oxidase and superoxide dismutase in stroke-prone SHR. Hypertension 38, 606-611.

Colwell R, Russell RGG \& Eastell R (1993) Factors affecting the assay of urinary 3-hydroxypyridinium cross-links of collagen as markers of bone resorption. European Journal of Clinical Investigation 23, 341-349.

Conlin PR, Chow D, Miller ER, Svetkey LP, Lin PH, Harsha DW, Moore TJ, Sacks FM \& Appel LJ (2000) The effects of dietary patterns on blood pressure control in hypertensive patients: results from the Dietary Approaches to Stop Hypertension (DASH) trial. American Journal of Hypertension 13, 949-955.

Dakskinamurti D \& Dakskinamurti MM (2001) Blood pressure regulation and micronutrients. Nutrition Research Reviews 14, 3-43.

Dallal GE (1990) PC-Size consultant - A program for sample size determinations. American Statistician 44, 243.

De Moss DL \& Wright GL (1998) Sex and strain differences in whole skeletal development in the rat. Calcified Tissue International 62, 153-157.

Department of Health (1991) Dietary Reference Values for Food Energy and Nutrients for the United Kingdom. London: HM Stationery Office.

Fleet JC (2001) DASH without the dash (of salt) can lower blood pressure. Nutrition Reviews 59, 291-293.

Galletti F, Rutledge A \& Triggle DJ (1991) Dietary sodium intake: influence on calcium channels and urinary calcium excretion in spontaneously hypertensive rats. Biochemical Pharmacology 41, 893-896.

Hall SL \& Greendale GA (1998) The relation of dietary vitamin C intake to bone mineral density: results from the PEPI study. Calcified Tissue International 63, 183-189.

Hatton DC, Scrogin KE, Metz JA \& McCarron DA (1989) Dietary calcium alters blood pressure reactivity in spontaneously hypertensive rats. Hypertension 13, 622-629.

Hoshino H, Kushida K, Takahashi M, Koyama S, Yamauchi H \& Inoue T (1998) Effects of low phosphate intake on bone and mineral metabolism in rats: evaluation by biochemical markers and pyridinium cross-link formation in bone. Annals of Nutrition and Metabolism 42, 110-118.

Institute of Medicine (1997) Dietary Reference Intakes: Calcium, Magnesium, Phosphorus, Vitamin D, and Fluoride. Washington, DC: Food and Nutrition Board, National Academy Press.

Izawa Y, Sagara K, Kadota T \& Makita T (1985) Bone disorders in spontaneously hypertensive rat. Calcified Tissue International 37, 605-607.

Jorde R, Sundsfjord J, Haug E \& Bønaa KH (2000) Relation between low calcium intake, parathyroid hormone, and blood pressure. Hypertension 35, 1154-1159.

Kadiri S \& Ajayi SO (2000) Variability in the relationship between serum creatinine and creatinine clearance in hypertensives and 
normotensives with normal renal function. African Journal of Medicine and Medical Sciences 29, 93-96.

Kalu DN, Liu CC, Salerno E, Hollis B, Echon R \& Ray M (1991) Skeletal response of ovariectomized rats to low and high doses of 17 beta-estradiol. Bone and Mineral 14, 175-187.

Karanja NMM, Obarzanek E, Lin P-H, McCullough ML, Phillips KM, Swain JF, Champagne CM \& Hoben KP (1999) Descriptive characteristics of the dietary patterns used in the Dietary Approaches to Stop Hypertension trial. Journal of the American Dietetic Association 99, S19-S27.

Lau K, Zikos D, Spirnak J \& Eby B (1984) Evidence for an intestinal mechanism in hypercalciuria of spontaneously hypertensive rats. American Journal of Physiology 247, E625-E633.

Lewanczuk RZ, Chen A \& Pang PK (1990) The effects of dietary calcium on blood pressure in spontaneously hypertensive rats may be mediated by parathyroid hypertensive factor. American Journal of Hypertension 3, 349-353.

Lin P, Ginty F, Appel L, Svetkey L, Bohannon A, Barclay D, Gannon R \& Aickin M (2001) Impact of sodium intake and dietary patterns on biochemical markers of bone and calcium metabolism. Journal of Bone and Mineral Research 16, S511.

Lucas PA, Brown RC, Drüeke T, Lacour B, Metz JA \& McCarron DA (1986) Abnormal vitamin D metabolism, intestinal calcium transport, and bone calcium status in the spontaneously hypertensive rat compared with its genetic control. Journal of Clinical Investigation 78, 221-227.

McCarron DA, Lucas PA, Shneidman RJ, LaCour B \& Drüeke T (1985) Blood pressure development of the spontaneously hypertensive rats after concurrent manipulations with dietary $\mathrm{Ca}^{2+}$ and $\mathrm{Na}^{+}$. Relation to intestinal $\mathrm{Ca}^{2+}$ fluxes. Journal of Clinical Investigation 76, 1147-1154.

McCarron DA, Pingree PA, Rubin RJ, Gaucher SM, Molitch M \& Krutzik S (1980) Enhanced parathyroid function in essential hypertension: a homeostatic response to urinary calcium leak. Hypertension 2, 162-168.

McCarron DA, Yung NN, Ugoretz BA \& Krutzik S (1981) Disturbances of calcium metabolism in the spontaneously hypertensive rat. Hypertension 3, I-162-I-167.

MacGregor GA \& Cappuccio P (1993) The kidney and essential hypertension: a link to osteoporosis? Journal of Hypertension 11, 781-785.

Mäkynen H, Kähönen M, Arvola P, Wuorela H, Vapaatalo H \& Pörsti I (1995) Dietary calcium and magnesium supplements in spontaneously hypertensive rats and isolated arterial activity. British Journal of Pharmacology 115, 1455-1462.

Metz A, Morris CD, Roberts LA, McClung MR \& McCarron DA (1999) Blood pressure and calcium intake are related to bone density in adult males. British Journal of Nutrition 81, 383-388.

Metz JA, Karanja N, Young EW, Morris CD \& McCarron DA (1990) Bone mineral density in spontaneous hypertension: differential effects of dietary calcium and sodium. American Journal of Medical Sciences 300, 225-230.

Moore TJ, Conlin PR, Ard J \& Svetkey LP (2001) DASH (Dietary Approaches to Stop Hypertension) Diet is effective treatment for stage 1 isolated systolic hypertension. Hypertension 38, 155-158.

Moore TJ, Vollmer WM, Appel LJ, Sacks FM, Svetkey LP, Vogt TM, Conlin PR, Simons-Morton DG, Carter-Edwards L \& Harsha DW (1999) Effect of dietary patterns on ambulatory blood pressure - results from the Dietary Approaches to Stop Hypertension (DASH) trial. Hypertension 34, 472-477.

Morton DJ, Barrett-Connor EL \& Schneider DL (2001) Vitamin $\mathrm{C}$ supplement use and bone mineral density in postmenopausal women. Journal of Bone and Mineral Research 16, 135-140.

National Research Council (1989) Recommended Dietary Allowances, 10th ed. Report of the Subcommittee on the Tenth Edition of the RDA. Food and Nutrition Board and the
Commission on Life Sciences. Washington, DC: National Academy Press.

New SA (2002) The role of the skeleton in acid-base homeostasis. Proceedings of the Nutrition Society 61, 151-164.

New SA, Bolton-Smith C, Grubb DA \& Reid DM (1991) Nutritional influences on bone mineral density: a cross-sectional study in premenopausal women. American Journal of Clinical Nutrition 65, 1831-1839.

New SA, Robins SP, Campbell MK, Martin JC, Garton MJ, Bolton-Smith C, Grubb DA, Lee SJ \& Reid DM (2000) Dietary influences on bone mass and bone metabolism: further evidence of a positive link between fruit and vegetable consumption and bone health? American Journal of Clinical Nutrition 71, 142-151.

Newaz MA, Nawal NNA, Rohaizan CH, Muslin N \& Gapor A (1999) $\alpha$-Tocopherol increased nitric oxide synthase activity in blood vessels of spontaneously hypertensive rats. American Journal of Hypertension 12, 839-844.

Obazanek E, Sacks FM, Vollmer WM, Bray GA, Miller III ER, Lin P-H, Karanja NM, Most-Windhauser MM, Moore TJ, Swain JF, Bales CW \& Proschan MA (2001) Effects on blood lipids of a blood pressure-lowering diet: the Dietary Approaches to Stop Hypertension (DASH) trial. American Journal of Clinical Nutrition 74, 80-89.

Patel VB, Richardson PJ \& Preedy VR (2000) Non-cardiac nucleic acid composition and protein synthesis rates in hypertension: studies on the spontaneously hypertensive rat (SHR) model. Clinica Chimica Acta 293, 167-179.

Patwardhan UN, Pahuja DN \& Samuel AM (2001) Calcium bioavailability: an in vivo assessment. Nutrition Research $\mathbf{2 1}$, $667-675$.

Pezeshk A \& Dalhouse AD (2000) Vitamin E, membrane fluidity, and blood pressure in hypertensive and normotensive rats. Life Sciences 67, 1881-1889.

Pörsti I (1992) Arterial smooth muscle contractions in spontaneously hypertensive rats on a high-calcium diet. Journal of Hypertension 10, 255-263.

Pratt DA, Daniloff Y, Duncan A \& Robins SP (1992) Automated analysis of the pyridinium crosslinks of collagen in tissue and urine using solid-phase extraction and reversed-phase highperformance liquid chromatography. Analytical Biochemistry 207, 168-175.

Rao RM, Yan Y \& Wu Y (1994) Dietary calcium reduces blood pressure, parathyroid hormone, and platelet cytosolic calcium responses in spontaneously hypertensive rats. American Journal of Hypertension 7, 1052-1057.

Reeves PG, Nielsen FH \& Fabey GC (1993) AIN-93 purified diets for laboratory rodents: final report of the American Institute of Nutrition ad hoc writing committee on the reformulation of the AIN-76A rodent diet. Journal of Nutrition $\mathbf{1 2 3}$ 1939-1951.

Remer T \& Manz F (1995) Potential renal acid load of foods and its influence on urine pH. Journal of the American Dietetic Association 95, 791-797.

Robins SP, Stead DA \& Duncan A (1994) Precautions in using an internal standard to measure pyridinoline and deoxypyridinoline in urine (letter). Clinical Chemistry 40, 2322-2323.

Sato T, Nara Y, Kato Y \& Yamori Y (1995) Effects of highcalorie diet on blood pressure and sodium retention in spontaneously hypertensive rats and Wistar-Kyoto rats. Journal of Diabetes and its Complications 9, 220-223.

Schedl HP, Miller DL, Pape JM, Horst RP \& Wilson HD (1984) Calcium and sodium transport and vitamin D metabolism in the spontaneously hypertensive rat. Journal of Clinical Investigation 73, 980-986.

Sebastian A, Harris ST, Ottaway JH, Todd KM \& Morris RC (1994) Improved mineral balance and skeletal metabolism in 
postmenopausal women treated with potassium bicarbonate. New England Journal of Medicine 330, 1776-1781.

Sellmeyer DE, Scholetter M \& Sebastian A (2002) Potassium citrate prevents increased urine calcium excretion and bone resorption induced by a high sodium chloride diet. Journal of Clinical Endocrinology and Metabolism 87, 2008-2012.

Sinha R, Smith JC \& Soares JH (1988) The effect of dietary calcium on bone metabolism in young and aged female rats using a shortterm in vivo model. Journal of Nutrition 10, 1217-1222.

Snedecor GW \& Cochran WG (1967) Statistical Methods. Ames, IA: Iowa State University Press.

Stendig-Lindberg G, Tepper R \& Leichter I (1993) Trabecular bone density in a two year controlled trial of peroral magnesium in osteoporosis. Magnesium Research 6, 155-163.

Svetkey LP, Simons-Morton D, Vollmer WM, Appel LJ, Conlin PR, Ryan DH, Ard J \& Kennedy BM (1999) Effects of dietary patterns on blood pressure. Subgroup analysis of the Dietary Approaches to Stop Hypertension (DASH) randomized clinical trial. Archives of Internal Medicine 159, 285-293.

Tolvanen J-P, Mäkynen H, Wu X, Hutri-Kähönen N, Ruskoaho H, Karjala K \& Pörsti I (1998) Effects of calcium and potassium supplements on arterial tone in vitro in spontaneously hypertensive rats. British Journal of Pharmacology 124, 119-128.

Touyz RM \& Milne FJ (1999) Magnesium supplementation attenuates, but does not prevent, development of hypertension in spontaneously hypertensive rats. American Journal of Hypertension 12, 757-765.

Tsuda K, Nishio I \& Masuyama Y (2001) Bone mineral density in women with hypertension. American Journal of Hypertension 14, 704-707.
Tucker KL, Hannan MT, Chen H, Cupples LA, Wilson PWF \& Kiel DP (1999) Potassium, magnesium and fruit and vegetable intakes are associated with greater bone mineral density in elderly men and women. American Journal of Clinical Nutrition 69, 727-736.

Vasdev S, Ford CA, Parai S, Longerich L \& Gadeg V (2000) Dietary $\alpha$-lipoic acid supplementation lowers blood pressure in spontaneously hypertensive rats. Journal of Hypertension 18, 567-573.

Vollmer WM, Sacks FM, Ard J, Appel LJ, Bray GA, SimonsMorton DG, Conlin PR, Svetkey LP, Erlinger TP, Moore TJ \& Karanja N (2001) Effects of DASH and sodium intake on blood pressure: Subgroup analysis of the DASH-Sodium trial. Annals of Internal Medicine 135, 1019-1028.

Wallach S \& Verch RL (1986) Tissue magnesium in spontaneously hypertensive rats. Magnesium 5, 33-38.

Weissman N \& Pileggi VJ (1974) Inorganic ions. In Clinical Chemistry: Principles and Techniques, pp. 639-755 [RJ Henry, DC Cannon and JW Winkleman, editors]. Hagerstown, MD: Harper and Row.

Wu X, Tolvanen J-P, Hutri-Kätiönen M, Mäkynen H, Korpela R, Rusoattio H, Karjala K \& Pörsti I (1998) Comparison of the effects of supplementation with whey mineral and potassium on arterial tone in experimental hypertension. Cardiovascular Research 40, 364-374.

Yoshioka M, Aoyama K \& Matsushita T (1985) Effects of ascorbic acid on blood pressure and ascorbic acid metabolism in spontaneously hypertensive rats ( $\mathrm{SH}$ rats). International Journal of Vitamin and Nutrition Research 55, 301-307. 